\title{
Hot Topics of Teenage Students' Cyberbullying Based on Web of Science
}

\author{
Wei Cao, Xiaohong Liu* \\ School of Education Science, Nanjing Normal University, Nanjing, China \\ Email: ^2093242714@qq.com
}

How to cite this paper: Cao, W., \& Liu, X. H. (2020). Hot Topics of Teenage Students' Cyberbullying Based on Web of Science. Open Journal of Social Sciences, 8, 495-509. https://doi.org/10.4236/jss.2020.84036

Received: March 29, 2020

Accepted: April 21, 2020

Published: April 24, 2020

Copyright $\odot 2020$ by author(s) and Scientific Research Publishing Inc. This work is licensed under the Creative Commons Attribution International License (CC BY 4.0).

http://creativecommons.org/licenses/by/4.0/ (c) (i) Open Access

\begin{abstract}
As many middle and high school students report experiencing cyberbullying on and off campus, more and more studies focus on this issue. By combing the researches on teenage students' cyberbullying, this paper is to provide a comprehensive analysis of the current research to identify the hot topics, and explore the prospects of teenage students' cyberbullying based on the research hot topics. The results show that the current research mainly focuses on four research topics: 1) definitions and characteristics of cyberbullying, 2) mental health problems caused by cyberbullying, 3) countermeasures of cyberbullying, and 4) relationship between gender difference and cyberbullying. Among them, the research topics of definitions and characteristics of cyberbullying, and mental health problems caused by cyberbullying are the core and hot topics. Research on the relationship between gender differences and cyberbullying has great development potential.
\end{abstract}

\section{Keywords \\ Cyberbullying, Teenage Students, Multidimensional Scaling Analysis, Knowledge Visualization}

\section{Introduction}

With the popularization of communication technology, teenagers have more access to electronic devices, which makes them more likely to be exposed to cyber risk. Cyberbullying which is one of the most common cyber risks refers to the deliberate act of repeatedly attacking others with electronic devices such as computers and mobile phones (Hutson, 2016; OECD, 2016). Cyberbullying can be done anonymously or at any time, and its nature includes physical and mental health problems such as depression, anxiety and physical problems (Hutson, Kelly, \& Militello, 2018), so the impact of cyberbullying on adolescents is more 
serious and lasting than traditional bullying. At present, many studies show that bullying and cyberbullying victimization is prevalent throughout the world (Beltran-Catalan, Zych, Ortega-Ruiz, \& Llorent, 2018). A survey of 17 high schools in Boston conducted by Kessel Schneider, O'Donnell and Smith (2015) found that the prevalence of cyberbullying victims increased from $15 \%$ to $21 \%$ over a six-year period (Kessel Schneider, O'Donnell, \& Smith, 2015). In a survey of Greek high school students, 62\% experienced cyberbullying (Gkiomisi, Gkrizioti, Gkiomisi, Anastasilakis, \& Kardaras, 2016). According to a study of the Cyberbullying Research Center, while the rates of cyberbullying victimization have varied over the years, the overall trend is on the rise. In 2017 , about $18.8 \%$ of the students have said they have been the victim of cyberbullying in their lifetime. In 2019 , about $36.5 \%$ of students reported that they had experienced cyberbullying (Patchin \& Hinduja, 2019). It suggests that more and more teenagers are likely to be experiencing cyberbullying.

In this study, the multidimensional scaling analysis tool was used to make a visual analysis of the literature on teenage students' cyberbullying in the core collection of Web of Science. The purpose of this paper is to provide a comprehensive analysis of the current research to identify the hot topics, and explore the prospects of teenage students' cyberbullying based on the research hot topics. It will provide direction for the following research in this field.

\section{Data Processing and Research Methods}

\subsection{Data Sources}

The data used in the study comes from the Web of Science (WoS) core collection database. The database is an important database for obtaining global academic information. A search was conducted to collect teenage students' cyberbullying research articles in the core collection of Web of Science. The search terms included "high school cyberbullying" or "middle school cyberbullying" or "secondary school cyberbullying" or "senior high school cyberbullying" or "senior middle school cyberbullying" or "junior high school cyberbullying" or "junior middle school cyberbullying". Based on the focus of research on the development of this field, search period was 1986-2019. 667 articles were obtained from WoS.

\subsection{Research Methods}

Bicomb (Bibliographic Item Co-Occurrence Matrix Builder) developed by professor Cui Lei of China Medical University is a visualization software for co-word network analysis. Bicomb has been widely used in information management in China because of its characteristics of openness and visualization. In this study, Bicomb and SPSS were used to visualize the literature related to teenage students' cyberbullying, to select keywords from the Web of Science database and systematically get the research trends in this field.

After searching the literature in WoS, the literature was deleted to avoid repetition and irrelevant literature, and 527 target articles were finally obtained. 
Cluster analysis was made on the keywords of 527 target articles by Bicomb and SPSS, and the research topics were determined. According to the results of cluster analysis, the multi-dimensional scale analysis was used to know the quadrant distribution of the research topics, and reveal the status and the hotspots of the research on teenage students' cyberbullying.

\section{Data Analysis and Results}

\subsection{Keywords List}

Keywords are highly concise contents of the paper. By counting the frequency of keywords in the research field of teenage students' cyberbullying, research hotspots can be determined. The first 28 keywords were selected as high-frequency keywords (see Table 1), which were with frequency $>11$, and the cumulative

Table 1. High-frequency keywords.

\begin{tabular}{|c|c|c|}
\hline Ranking & Keywords & Frequency \\
\hline 1 & cyberbullying & 407 \\
\hline 2 & bullying & 161 \\
\hline 3 & adolescents & 131 \\
\hline 4 & cyber victimization & 59 \\
\hline 5 & adolescence & 56 \\
\hline 6 & victimization & 51 \\
\hline 7 & bystander & 27 \\
\hline 8 & victims & 25 \\
\hline 9 & perpetration & 23 \\
\hline 10 & gender & 22 \\
\hline 11 & traditional bullying & 21 \\
\hline 12 & school & 20 \\
\hline 13 & school bullying & 19 \\
\hline 14 & suicide & 17 \\
\hline 15 & mental health & 17 \\
\hline 16 & prevention & 16 \\
\hline 17 & self-esteem & 16 \\
\hline 18 & coping strategies & 15 \\
\hline 19 & aggression & 15 \\
\hline 20 & moral disengagement & 15 \\
\hline 21 & depression & 14 \\
\hline 22 & internet & 14 \\
\hline 23 & empathy & 14 \\
\hline 24 & intervention & 14 \\
\hline 25 & cyber harassment & 12 \\
\hline 26 & suicidal ideation & 12 \\
\hline 27 & parents & 12 \\
\hline 28 & gender differences & 12 \\
\hline
\end{tabular}


frequency was $48.4 \%$, which met the analysis criteria. It can be seen from Table 1, except for "cyberbullying", the top ten keywords are: "bullying", "adolescents", "cyber victimization", "adolescence", "victimization", "bystander", "victims", "perpetration", "gender", and "traditional bullying". This result indicates that the research on teenage students' cyberbullying mostly focuses on the forms and gender of bullying. The inner relationship between keywords needs further data mining.

\subsection{The Multi-Dimensional Scaling Analysis}

Multidimensional scaling analysis is a kind of data analysis method that inputs a matrix containing quantitative measurement value, simplifies the research object of multidimensional space to a low-dimensional space for positioning, analysis and classification, while retaining the original relationship between objects (Borg \& Groenen, 2006). Through multidimensional scaling analysis, we can understand the relationship between research topics.

Firstly, the target articles were imported into Bicomb, and the $28 \times 28$ word matrix was obtained. Secondly, the word matrix was imported into SPSS to generate a $28 \times 28$ high-frequency keywords similarity matrix. Thirdly, the dissimilarity matrix was obtained by subtracting the values in the similarity matrix from 1. Fourthly, a multidimensional scaling analysis was performed on the dissimilarity matrix. The results show that Stress $=0.27$ and RSQ $=0.67$, indicating that the research has a good fitting effect (RSQ $>0.6$ ), which can reflect the internal relationship between keywords in the research of teenage students' cyberbullying. The result of the multidimensional scaling analysis is presented in Figure 1, the topic division is based on the clustering analysis results.

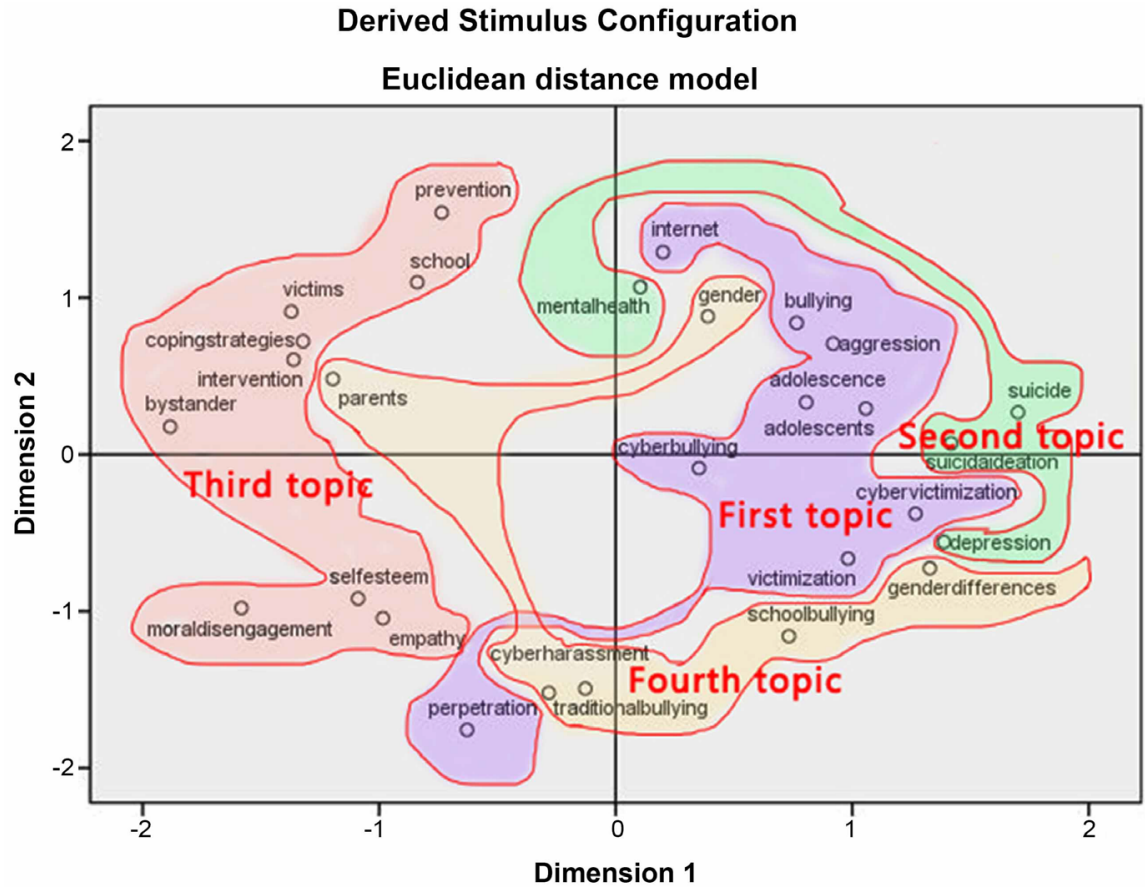

Figure 1. The result of multidimensional scaling analysis. 
In the multidimensional scaling analysis diagram, centrality is used as the $\mathrm{X}$-axis, Density as the $\mathrm{Y}$-axis, and the median or average of the two axes as the origin of coordinates. Quadrant 2: The topic of this quadrant cluster has high density values and low centrality. Such themes are mature in the field but are not research centers and are not important for current development prospects. Quadrant 4: The topic of this quadrant cluster is the basic theme of this research field. It has great influence in the field, but it has not been well developed and has great development potential.

As shown in Figure 1, the first topic (definitions and characteristics of teenage students' cyberbullying) and the second topic (mental health problems caused by teenage students' cyberbullying) are in the first quadrant. In Figure 1, the topic in the first quadrant indicates that the topics have a high density and centrality. The keywords within the topics are closely related to each other, which are the core and hot spot of this research field. The third topic (countermeasures of teenage students' cyberbullying) is in the second quadrant. The topic of this quadrant has high density and low centrality. Such topics are mature in the field, but they are not yet research centers. The fourth topic (relationship between gender difference and teenage students' cyberbullying) is in the fourth quadrant. The topics in the fourth quadrant are the basic topic of research on teenage students' cyberbullying, but they have not been well developed and have great development potential (Xie, Zhang, \& Duan, 2020).

\section{Discussion and Conclusion}

In this section, we review the literature according to the four research topics, and introduce the current research overview in the four topics.

\subsection{Definitions and Characteristics of Teenage Students' Cyberbullying}

Smith et al. (2008) define cyberbullying as: "An aggressive, intentional act carried out by a group or individual, using electronic forms of contact, repeatedly and over time against a victim who cannot easily defend him or herself". Tokunaga (2010) suggests that cyberbullying is any behavior performed through electronic or digital media by individuals or groups that repeatedly communicates hostile or aggressive messages intended to inflict harm or discomfort on others. Federal Partners in Bullying Prevention suggests that cyberbullying is bullying that takes place over digital devices like cell phones, computers, and tablets. Cyberbullying can occur through SMS, texts, apps, online in social media, forums, or games where people can send, post, or share negative, harmful, false, or mean content about someone else (U.S. Department of Health and Human Services, 2019). From the above definitions, the essential characteristics of teenage students' cyberbullying include electronic media, intentional attacks, repetitive bullying for a long time, and the power imbalance between cyberbullies and victims. This inequality of rights is mainly reflected in the relatively anonymous online 
environment of the bully, the core status of the bully in the social network, the victim's appearance characteristics, learning problems and other weaknesses (Ersilia \& Annalaura, 2009).

There is a significant overlap between cyberbullying and school bullying (Baldry, Farrington, \& Sorrentino, 2016). Raskauskas and Stoltz (2007) found that $94 \%$ of cyberbullies were also traditional bullies in a survey. There is also a large percentage of overlap between school bullying victims and cyberbullying victims. $59.7 \%$ of cyberbullying victims were also school bullying victims, and $36.3 \%$ of school bullying victims were also cyberbullying victims (Schneider, O'Donnell, Stueve, \& Coulter, 2012). However, the potential danger of cyberbullying is even greater, mainly reflected in the following four aspects (King, Walpole, \& Lamon, 2007; Nixon, 2014; Patchin \& Hinduja, 2006; Ybarra \& Mitchell, 2004):

1) Cyberbullying is not limited by time and space. The bully can continue school bullying outside the school. They can use phones, text messages, e-mails, pictures, videos, chat rooms, websites, etc. to threaten and harass others everywhere at any time.

2) Anonymity of cyberbullies. The physical distance and invisibility of cyberbullying make it impossible for the cyberbullies to observe the immediate response of the victims, which reduces the empathy that the cyberbullies develop when seeing the victim's pain, and makes young cyberbullies more aggressive than in real life. In addition, anonymous cyberspace also provides a safer environment for the cyberbullies to prevent victims from retaliating.

3) The potential audience for cyberbullying is wide. With the support of technical tools, the cyberbullies can quickly spread bullying content across platforms to the wider audience. Once the content is spread, it will not only be difficult to control and delete, but also cause repeated harm to the victims, and make cyberbullying among teenagers more common, obvious and lasting.

4) There is a lack of regulation in cyberspace, and it is difficult to define regulatory responsibilities.

Middle and high school students are in adolescence. The complexity of peer relationships and social cognitive skills are increasing. It is easier to bully others by manipulating social relationships (Sutton, Smith, \& Swettenham, 1999). As a result, cyberbullying occurs more easily and frequently among teenage students. There are three types of risks that teens face online (Vismara, Toaff, Pulvirenti, Settanni, \& Marotta, 2017): the first one is Internet technology risks, such as exposure to illegal or potentially harmful content, being tracked by the Internet, and receiving threatening anonymous messages; a second one regards privacy and security risks. Excessive sharing of personal information on social networking sites leads to identity impersonation or revealed privacy; finally, consumer risks related to Web-based advertising and marketing that exploit the lack of fully developed critical thinking skills leading to overspending and fraudulent transactions. 


\subsection{Mental Health Problems Caused by Teenage Students' Cyberbullying}

Cyberbullying does not directly cause actual physical damage to the victim, but psychological, social and emotional damage in nature (Dooley, Pyzalski, \& Cross, 2009). It usually manifested as psychological problems, peer problems, and emotional problems. As information spreads, ridicule and insult can cause overexposure. When the victims are unable to control cyberbullying, they will feel powerless. Thus, they are more likely to be affected by negative psychology, such as depression, anxiety, emotional distress and suicidal tendency, etc., which exacerbates the harm of cyberbullying. A survey of high school students found that the victims of cyberbullying and school bullying were more than four times more likely to suffer from depression and five times more likely to have suicidal ideation than those who had not been bullied (Schneider, O'Donnell, Stueve, \& Coulter, 2012). In a study on 15,425 high school students, $15 \%$ cybervictims reported making a suicide attempt compared to $5 \%$ of those not cyberbullied (Messias, Kindrick, \& Castro, 2014). A survey of 4886 Canadian students in Grades 7 - 12, the odds ratio of mental health, psychological distress, and suicidal ideation were 5.02, 5.91, and 6.17 (Sampasa-Kanyinga, 2017). In a meta-analysis, cybervictims are at greater risk of self-harm and suicidal behaviors than non-victims (John, Glendenning, Marchant, Montgomery, Stewart, Wood et al., 2018). The victim of cyberbullying is more prone to psychological stress and inferiority, and lower self-esteem is not conducive to self-regulation and adaptation to school life in the learning environment, which affects academic performance and school performance, leading to academic failure (Chao \& Yu, 2017). In addition, the study demonstrates that cyberbullying is a strong risk factor for the later development of psychopathologic behaviors (Kim, Leventhal, Koh, Hubbard, \& Boyce, 2006). Cyberbullies have worse subjective health than those who are not involved. The more adolescents engage in cyber aggression, the more loneliness they feel, the lower self-worth is, the fewer mutual friendships they have, the fewer the ratings of social acceptance and popularity by peers are. These consequences, in turn, reduce the perception of learning and school for cyberbullies (Betts, Spenser, \& Gardner, 2017; Jacobs, Völlink, Dehue, \& Lechner, 2014). Ybarra and Mitchell (2004) reported that $34.7 \%$ of aggressor-only youth showed problem behavior, $27.8 \%$ had low school commitment, $46 \%$ indicated cigarette or alcohol use, and $10.2 \%$ were severely depressed.

The stressor experienced in one environment will be demonstrated in another, and this spillover theory exists between cyberbullying experiences and the school environment (Timmons \& Margolin, 2014). Even though cyberbullying usually occurs outside school, both cyberbullies and victims have a certain level of negative perception of the school. Many students who have experienced cyberbullying are afraid of going to school, and even escalate their fears into active avoidance, which manifested as truancy or dropout (Sourander, Klomek, Ikonen, Lindroos, \& Koskelainen, 2010). Cyberbullies show a high degree of perceived 
difficulty, distrust of their classmates, consider the school unsafe, and hold a negative attitude towards the school (Baya \& Uçanok, 2012). Students who are both victims of traditional bullying and cyberbullying, or both victims of cyberbullying and cyberbullies, have more complex mental health issues and may have all of the above, making them the most troubled group. In a large, nationally representative sample of high school students in the United States, Messias et al. (2014) found that $12.4 \%$ of students who suffered from cyberbullying had suicidal ideation, $11.9 \%$ had suicide plan, and $13.7 \%$ had suicidal attempt. However, $23.2 \%$ of students who suffered from both cyberbullying and school bullying had suicidal ideation, $23.9 \%$ had suicide plan, and $27.3 \%$ had suicidal attempt. Thus, students who suffered from both school bullying and cyberbullying may have more serious mental health risks, and even need psychological treatment.

\subsection{Countermeasures of Teenage Students' Cyberbullying}

\subsubsection{Student Level: Stop Bullying Information and Seek Social Support Technically}

In the face of cyberbullying, students will have aggressive responses to revenge against the bully, arbitrary responses to ignore bullying information, or passive responses of no-reprisal or even obedience (Dooley, Shaw, \& Cross, 2012). Revenging the bully may let events out of control, and make the victim potentially cyberbullies, forming a vicious circulation of cyberbullying. The victims often keep silent because of fear of the reaction of cyberbullies or teachers. Students consider that the most desirable strategy is to stop bullying information, change contact information, or seek social support (Chao \& Yu, 2017; Roberto, Eden, Savage, Ramos-Salazar, \& Deiss, 2014b). Selkie et al. (2018) conducted a qualitative survey of adolescents aged 14 - 18, summarizing two major strategies for personal and systematic intervention in teenage students' cyberbullying. From the individual level, students should stop negative information and report the bully to social platforms. At the same time, they should leave social media for a short time to communicate with parents or teachers. A companion of victim can assist them in seeking help.

\subsubsection{School Level: Take the Prevention and Intervention Measures}

The risk factors between cyberbullying and school bullying are similar. Even if the bullying information is received outside school, more than half of the victims know that the cyberbullies come from the same school and will bring the contradiction back to the school, so interventions should always focus on solving antisocial behaviors (Baldry, Farrington, \& Sorrentino, 2015). 36 states in the United States have provisions in their education laws that prohibit cyberbullying, and point out that the school has jurisdiction over cyberbullying outside of school if students' behavior creates a hostile school environment (U.S. Department of Education, 2011). Most teenage students' cyberbullying prevention and intervention programs are improved on the basis of traditional school bullying 
(Tangen \& Campbel, 2010), which can have a multi-purpose impact on effectively improving the problem of cyberbullying. Therefore, it is reasonable prevention and intervention methods for schools to focus on both cyberbullying and traditional bullying. In addition, the prevention and intervention methods can be carried out from the following aspects (Beale \& Hall, 2007; Feinberg, \& Robey, 2009).

1) Making the policies related to students' use of the electronic devices. Besides, the policy should clarify what is cyberbullying and specify the negative consequences of cyberbullying.

2) Adopting thematic education methods to establish students' safety awareness of cyberbullying. The school integrates the thematic activities of network security education, media literacy education and bullying prevention into classroom teaching. For example, a lecture or salon on the subject of teenage students' cyberbullying should be held to let students find information about cyberbullying, and learn from each other about the prevention and countermeasures of teenage students' cyberbullying.

3) All school staff are trained to be alerted to the cyberbullying issues in time, understand what school bullying and cyberbullying are, and how to identify victims and bullies. As long as they are aware of the risks of cyberbullying, they are willing to intervene in teenage students' cyberbullying.

4) School-family-community partnerships should be established to promote cooperation between school, teachers, parents, and communities. Schools should encourage parents to discuss cyberbullying and its adverse consequences with their children. Schools can connect with local cyberbullying communities and invite relevant cyberbullying experts to schools to discuss with parents and students how to properly use the Internet, prevent cyberbullying and how to deal with it when they are cyberbullied.

\subsubsection{National Level: Carry Out Various Forms of Social Practice Activities to Raise Bullying Prevention Awareness}

There are various forms of publicity and promotion of anti-cyberbullying in the world, such as establishing a special bullying website, launching a bullying prevention week or bullying prevention month, conducting seminars, and participating in the discussion of bullying prevention topics, etc. The reason for doing so is to enhance the awareness of the whole people on the prevention of traditional bullying and cyberbullying, and to strengthen the sense of social responsibility. European countries were the first to launch the Safer Internet Day (ConnectSafely, 2019), which aims to create a safer and better Internet. A global, community-led approach allows everyone to use technology responsibly, respectfully, critically, and creatively. At present, "Safer Internet Day" series of events have been held in more than 100 countries.

Australia has established the National Day of Action against Bullying and Violence (NDA) in 2009, giving schools and young people the opportunity to participate in anti-bullying and anti-cyberbullying seminars to promote the im- 
provement of bullying programs (Safe and Supportive School Communities, 2019). In order to increase the awareness of network security among teenagers, Canada established the Internet security committee in relevant local departments, and invited professionals to design Internet security programs for schools, while educating students about the importance of Internet security and reeducating parents, and guiding teenagers' network behavior through family education. The United States has designated October each year as the National Bullying Prevention Awareness Month, aiming to raise the prevention awareness of bullying among all people (U.S. Department of Education, 2014). There are various forms of activities, such as launching a nationwide cyberbullying prevention topic on social network sites, collecting individual or group countermeasures, holding special lectures or seminars on teenage students' cyberbullying, and sharing researches on how families, schools, and communities take effective actions to stop bullying and reduce its harmful effects. America relies on relevant platforms to provide advice on bullying responses. For example, the US Substance Abuse and Mental Health Services Administration (SAMHSA) has launched a new mobile app that can provide parents, caregivers and teachers with important information on bullying prevention, and can help parents and children have a conversation. The U.S. Department of Health and Human Services (HHS) also has a dedicated website (https://www.stopbullying.gov/) for coordinating policy, research, and communication on bullying and cyberbullying issues. The website gives advice on bullying and cyberbullying prevention from multiple perspectives of students, schools, communities, policies, and bystanders (U.S. Department of Health and Human Services, 2019).

\subsection{Relationship between Gender Difference and Teenage Students' Cyberbullying}

The relationship between gender difference and cyberbullying in teenage students has not yet been clearly established (Kalliope, Eirini, Andrie, Charalampos, Tzavara, Clive et al., 2018). From the existing research, this gender difference may be related to cultural difference and age. Görzig and Ólafsson (2013) surveyed teenagers in 25 European countries and found that girls were more likely to be cyberbullies. Cross et al. (2012) suggested that girls were more likely to be targets of cyberbullying than were boys. Roberto et al. (2014a) found that adolescents have no significant gender difference in cyberbullying. Gender difference in cyberbullying may be related to cultural difference. Girls in eastern culture are generally considered submissive and gentle, and may be more reluctant to participate in cyberbullying than western girls (Natalie \& McBride, 2016). Barlett and Coyne (2014) explored the relationship between cyberbullying and gender difference from an age perspective, and found that such the difference was most obvious in the stage of adolescence and was mitigated with age. Women in early adolescence may be more likely to participate in cyberbullying because they mature relatively early and have a more complex understanding of social structure. As they grow up, men catch up in later adolescence and show 
higher participation in cyberbullying.

Middle and high school students also have gender difference in the degree of cyberbullying victimization and responses. More than half of the boys who had experienced cyberbullying reported that they had less negative emotion caused by cyberbullying than girls, and were less affected by cyberbullying than traditional bullying. They could recover from the negative effects faster (Fridh, Lindström, \& Rosvall, 2015; Sakellariou, Carroll, \& Houghton, 2012). Girls who had experienced cyberbullying had a negative impact on their learning outlook and school value, and were more likely to truancy and took a negative attitude towards school (Betts, Spenser, \& Gardner, 2017). However, when faced with cyberbullying, girls are more likely than boys to seek social support for respect, understanding, and a sense of social belonging (Fridh, Lindström, \& Rosvall, 2015). In addition, after witnessing cyberbullying, girls have stronger empathy than boys and are more likely to protect victims than to reinforce bullying (Thornberg, Wänström, Hong, \& Espelage, 2017).

\section{Funding}

This research was supported by the Priority Academic Program Development of Jiangsu Higher Education Institutions in China.

\section{Author Contributions}

Xiaohong Liu has designed the research. Wei Cao analyzed the data, and prepared the first draft of the paper. Xiaohong Liu as the corresponding author contributed to the revision. All authors approved the final draft.

\section{Conflicts of Interest}

The authors declare no conflicts of interest regarding the publication of this paper.

\section{References}

Baldry, A. C., Farrington, D. P., \& Sorrentino, A. (2015). “Am I at Risk of Cyberbullying"? A Narrative Review and Conceptual Framework for Research on Risk of Cyberbullying and Cybervictimization: The Risk and Needs Assessment Approach. Aggression and Violent Behavior, 23, 36-51. https://doi.org/10.1016/j.avb.2015.05.014

Baldry, A. C., Farrington, D. P., \& Sorrentino, A. (2016). Cyberbullying in Youth: A Pattern of Disruptive Behaviour. Psicología Educativa, 22, 19-26. https://doi.org/10.1016/j.pse.2016.02.001

Barlett, C., \& Coyne, S. M. (2014). A Meta-Analysis of Sex Differences in Cyber-Bullying Behavior: The Moderating Role of Age. Aggressive Behavior, 40, 474-488. https://doi.org/10.1002/ab.21555

Bayar, Y., \& Uçanok, Z. (2012). School Social Climate and Generalized Peer Perception in Traditional and Cyberbullying Status. Educational Sciences: Theory and Practice, 12, 2352-2358. https://eric.ed.gov/?id=EJ1002851

Beale, A. V., \& Hall, K. R. (2007). Cyberbullying: What School Administrators (and Parents) Can Do. The Clearing House, 81, 8-12. https://doi.org/10.3200/TCHS.81.1.8-12 
Betts, L. R., Spenser, K. A., \& Gardner, S. E. (2017). Adolescents' Involvement in Cyber Bullying and Perceptions of School: The Importance of Perceived Peer Acceptance for Female Adolescents. Sex Roles, 77, 471-481. https://doi.org/10.1007/s11199-017-0742-2

Beltran-Catalán, M., Zych, I., Ortega-Ruiz, R., \& Llorent, V. J. (2018). Victimisation through Bullying and Cyberbullying: Emotional Intelligence, Severity of Victimisation and Technology Use in Different Types of Victims. Psicothema, 30, 183-188.

Borg, I., \& Groenen, P. J. F. (2006). Modern Multidimensional Scaling: Theory and Applications. Journal of Educational Measurement, 40, 277-280. https://doi.org/10.1111/j.1745-3984.2003.tb01108.x

Chao, C.-M., \& Yu, T.-K. (2017). Associations among Different Internet Access Time, Gender and Cyberbullying Behaviors in Taiwan's Adolescents. Frontiers in Psychology, 8, 1104. https://doi.org/10.3389/fpsyg.2017.01104

ConnectSafely (2019). About Safer Internet Day USA. https://saferinternetday.us/aboutsidusa

Cross, D., Shaw, T., Epstein, M., Monks, H., Dooley, J., \& Hearn, L. (2012). Cyberbullying in Australia: Is School Context Related to Cyberbullying Behaviour. In Q. Li, D. Cross, \& P. K. Smith (Eds.), Cyberbullying in the Global Playground: Research from International Perspectives (pp. 75-98). Hoboken, NJ: Wiley-Blackwell.

https://doi.org/10.1002/9781119954484.ch5

Dooley, J. J., Pyzalski, J., \& Cross, D. (2009). Cyberbullying versus Face-to-Face Bullying: A Theoretical and Conceptual Review. Journal of Psychology, 217, 182-188. https://doi.org/10.1027/0044-3409.217.4.182

Dooley, J. J., Shaw, T., \& Cross, T. (2012). The Association between the Mental Health and Behavioural Problems of Students and Their Reactions to Cyber-Victimization. European Journal of Developmental Psychology, 9, 275-289. https://doi.org/10.1080/17405629.2011.648425

Ersilia, M., \& Annalaura, N. (2009). Cyberbullying Definition and Measurement. Journal of Psychology, 217, 230-232. https://doi.org/10.1027/0044-3409.217.4.230

Feinberg, T., \& Robey, N. (2009). Cyberbullying: Intervention and Prevention Strategies. National Association School Psychologists, 38, 1-4.

http://www.clubtnt.org/safeOnline/printResources/cyberbullyingInterventionNprevent ionsStrategies.pdf

Fridh, M., Lindström, M., \& Rosvall, M. (2015). Subjective Health Complaints in Adolescent Victims of Cyber Harassment: Moderation through Support from Parents/Friends-A Swedish Population-Based Study. BMC Public Health, 15, Article No. 949. https://doi.org/10.1186/s12889-015-2239-7

Gkiomisi, A., Gkrizioti, M., Gkiomisi, A., Anastasilakis, D. A., \& Kardaras, P. (2016). Cyberbullying among Greek High School Adolescents. The Indian Journal of Pediatrics, 84, 364-368. https://doi.org/10.1007/s12098-016-2256-2

Görzig, A., \& Ólafsson, K. (2013). What Makes a Bully a Cyberbully? Unravelling the Characteristics of Cyberbullies across Twenty-Five European Countries. Journal of Children and Media, 7, 9-27. https://doi.org/10.1080/17482798.2012.739756

Hutson, E. (2016). Cyberbullying in Adolescence: A Concept Analysis. Advances in Nursing Science, 39, 60-70. https://doi.org/10.1097/ANS.0000000000000104

Hutson, E., Kelly, S., \& Militello, L. K. (2018). Systematic Review of Cyberbullying Interventions for Youth and Parents with Implications for Evidence-Based Practice. Worldviews on Evidence-Based Nursing, 15, 72-79. https://doi.org/10.1111/wvn.12257

Jacobs, N. C., Völlink, T., Dehue, F., \& Lechner, L. (2014). Online Pestkoppenstoppen: 
Systematic and Theory-Based Development of a Web-Based Tailored Intervention for Adolescent Cyberbully Victims to Combat and Prevent Cyberbullying. BMC Public Health, 14, Article No. 396. https://doi.org/10.1186/1471-2458-14-396

John, A., Glendenning, A. C., Marchant, A., Montgomery, P., Stewart, A., Wood, S. et al. (2018). Self-Harm, Suicidal Behaviors, and Cyberbullying in Children and Young People: Systematic Review. Journal of Medical Internet Research, 20, e129.

https://doi.org/10.2196/jmir.9044

Kalliope, A., Eirini, M., Andrie, E. K., Charalampos, M., Tzavara, C. K., Clive, R. et al. (2018). Cross-National Aspects of Cyberbullying Victimization among 14-17-Year-Old Adolescents across Seven European Countries. BMC Public Health, 18, Article No. 800. https://doi.org/10.1186/s12889-018-5682-4

Kessel Schneider, S., O’Donnell, L., \& Smith, E. (2015). Trends in Cyberbullying and School Bullying Victimization in a Regional Census of High School Students 2006-2012. Journal of School Health, 85, 611-620. https://doi.org/10.1111/josh.12290

Kim, Y. S., Leventhal, B. L., Koh, Y. J., Hubbard, A., \& Boyce, W. T. (2006). School Bullying and Youth Violence: Causes or Consequences of Psychopathologic Behavior? Archives of General Psychiatry, 63, 1035-1041. https://doi.org/10.1001/archpsyc.63.9.1035

King, J. E., Walpole, C. E., \& Lamon, K. (2007). Surf and Turf Wars Online-Growing Implications of Internet Gang Violence. Journal of Adolescent Health Official Publication of the Society for Adolescent Medicine, 41, s66-s68. https://doi.org/10.1016/j.jadohealth.2007.09.001

Messias, E., Kindrick, K., \& Castro, J. (2014). School Bullying, Cyberbullying, or Both: Correlates of Teen Suicidality in the 2011 CDC Youth Risk Behavior Survey. Comprehensive Psychiatry, 55, 1063-1068. https://doi.org/10.1016/j.comppsych.2014.02.005

Natalie, W., \& McBride, C. (2016). To Use Facebook for Good: Usage, Cyberbullying Involvement, and Perceived Social Support. Child Studies in Asia-Pacific Contexts, 6, 59-72. https://doi.org/10.5723/csac.2016.6.2.059

Nixon, C. L. (2014). Current Perspectives-The Impact of Cyberbullying on Adolescent Health. Medicine and Therapeutics, 5, 143-158. https://doi.org/10.2147/AHMT.S36456

OECD (2016). Trends Shaping Education 2016.

Patchin, J. W., \& Hinduja, S. (2006). Bullies Move beyond the Schoolyard: A Preliminary Look at Cyberbullying. Youth Violence and Juvenile Justice, 4, 148-169. https://doi.org/10.1177/1541204006286288

Patchin, J. W., \& Hinduja, S. (2019). Summary of Our Cyberbullying Research (2007-2019). https://cyberbullying.org/summary-of-our-cyberbullying-research

Raskauskas, J., \& Stoltz, A. D. (2007). Involvement in Traditional and Electronic Bullying among Adolescents. Developmental Psychology, 43, 564-475. https://doi.org/10.1037/0012-1649.43.3.564

Roberto, A. J., Eden, J., Savage, M. W., Ramos-Salazar, L., \& Deiss, D. M. (2014a). Prevalence and Predictors of Cyberbullying Perpetration by High School Seniors. Communication Quarterly, 62, 97-114. https://doi.org/10.1080/01463373.2013.860906

Roberto, A. J., Eden, J., Savage, M. W., Ramos-Salazar, L., \& Deiss, D. M. (2014b). Outcome Evaluation Results of School-Based Cybersafety Promotion and Cyberbullying Prevention Intervention for Middle School Students. Health Communication, 29, 1029-1042. https://doi.org/10.1080/10410236.2013.831684

Safe and Supportive School Communities (2019). National Day of Action against Bullying and Violence. https://bullyingnoway.gov.au/nationalday

Sakellariou, T., Carroll, A., \& Houghton, S. (2012). Rates of Cyber Victimization and 
Bullying among Male Australian Primary and High School Students. School Psychology International, 33, 533-549. https://doi.org/10.1177/0143034311430374

Sampasa-Kanyinga, H. (2017). Co-Occurring Cyberbullying and School Bullying Victimization and Associations with Mental Health Problems among Canadian Middle and High School Students. Violence \& Victims, 32, 671-687. https://doi.org/10.1891/0886-6708.VV-D-16-00031

Schneider, S. K., O’Donnell, L., Stueve, A., \& Coulter, R. W. S. (2012). Cyberbullying, School Bullying, and Psychological Distress: A Regional Census of High School Students. American Journal of Public Health, 102, 171-177. https://doi.org/10.2105/AJPH.2011.300308

Selkie, E., Evans, Y., Ton, A., Midamba, N., \& Moreno, M. A. (2018). Ideas for Addressing Electronic Harassment among Adolescents Attending a Video Blogging Convention. BMC Public Health, 18, Article No. 973.

https://doi.org/10.1186/s12889-018-5907-6

Smith, P. K., Mahdavi, J., Carvalho, M., Fisher, S., \& Tippett, N. (2008). Cyberbullying: Its Nature and Impact in Secondary School Pupils. Journal of Child Psychology and Psychiatry, 49, 376-385. https://doi.org/10.1111/j.1469-7610.2007.01846.x

Sourander, A., Klomek, A. B., Ikonen, M., Lindroos, J., Luntamo, T., \& Koskelainen, M. et al. (2010). Psychosocial Risk Factors Associated with Cyberbullying among Adolescents: A Population-Based Study. Archives of General Psychiatry, 67, 720-728. https://doi.org/10.1001/archgenpsychiatry.2010.79

Sutton, J., Smith, P. K., \& Swettenham, J. (1999). Bullying and "Theory of Mind": A Critique of the "Social Skills Deficit" View of Anti-Social Behaviour. Social Development, 8, 117-127. https://doi.org/10.1111/1467-9507.00083

Tangen, D., \& Campbell, M. (2010). Cyberbullying Prevention: One Primary School's Approach. Australian Journal of Guidance and Counselling, 20, 225-234. https://doi.org/10.1375/ajgc.20.2.225

Thornberg, R., Wänström, L., Hong, J. S., \& Espelage, D. L. (2017). Classroom Relationship Qualities and Social-Cognitive Correlates of Defending and Passive Bystanding in School Bullying in Sweden: A Multilevel Analysis. Journal of School Psychology, 63, 49-62. https://doi.org/10.1016/j.jsp.2017.03.002

Timmons, A. C., \& Margolin, G. (2014). Family Conflict, Mood, and Adolescents' Daily School Problems: Moderating Roles of Internalizing and Externalizing Symptoms. Child Development, 86, 241-258. https://doi.org/10.1111/cdev.12300

Tokunaga, R. S. (2010). Following You Home from School: A Critical Review and Synthesis of Research on Cyberbullying Victimization. Computers in Human Behavior, 26, 277-287. https://doi.org/10.1016/j.chb.2009.11.014

U.S. Department of Education (2011). Analysis of State Bullying Laws and Policies. https://www2.ed.gov/rschstat/eval/bullying/state-bullying-laws/state-bullying-laws.pdf

U.S. Department of Health and Human Services (2019). What Is Cyberbullying. https://www.stopbullying.gov/cyberbullying/what-is-it/index.html

U.S. Department of Education (2014). Working Together to Provide Resources to Prevent Bullying This Month and Every Month.

https://blog.ed.gov/2014/10/working-together-to-provide-resources-to-prevent-bullyin g-this-month-and-every-month

Vismara, M. F. M., Toaff, J., Pulvirenti, G., Settanni, C., \& Marotta, R. (2017). Internet Use and Access, Behavior, Cyberbullying, and Grooming: Results of an Investigative Whole City Survey of Adolescents. Interactive Journal of Medical Research, 6, e9. 
https://doi.org/10.2196/ijmr.6231

Xie, H., Zhang, Y., \& Duan, K. (2020). Evolutionary Overview of Urban Expansion Based on Bibliometric Analysis in Web of Science from 1990 to 2019. Habitat International, 95, Article ID: 102100. https://doi.org/10.1016/j.habitatint.2019.102100

Ybarra, M. L., \& Mitchell, K. J. (2004). Online Aggressor/Targets, Aggressors, and Targets: A Comparison of Associated Youth Characteristics. Journal of Child Psychology and Psychiatry, 45, 1308-1316. https://doi.org/10.1111/j.1469-7610.2004.00328.x 